\title{
Voler le feu du savoir pour l'éclairage commun
}

Éditorial

\section{Gil Bartholeyns, Damien Kunik et Annabel Vallard}

\section{(2) OpenEdition}

Journals

Édition électronique

URL : https://journals.openedition.org/tc/16155

DOI : $10.4000 /$ tc. 16155

ISSN : 1952-420X

Éditeur

Éditions de l'EHESS

\section{Édition imprimée}

Date de publication : 8 décembre 2021

Pagination : 6-9

ISBN : 978-2-7132-2875-9

ISSN : 0248-6016

Référence électronique

Gil Bartholeyns, Damien Kunik et Annabel Vallard, « Voler le feu du savoir pour l'éclairage commun », Techniques \& Culture [En ligne], 76 | 2021, mis en ligne le 09 décembre 2021, consulté le 29 septembre 2022. URL : http://journals.openedition.org/tc/16155 ; DOI : https://doi.org/10.4000/tc.16155 


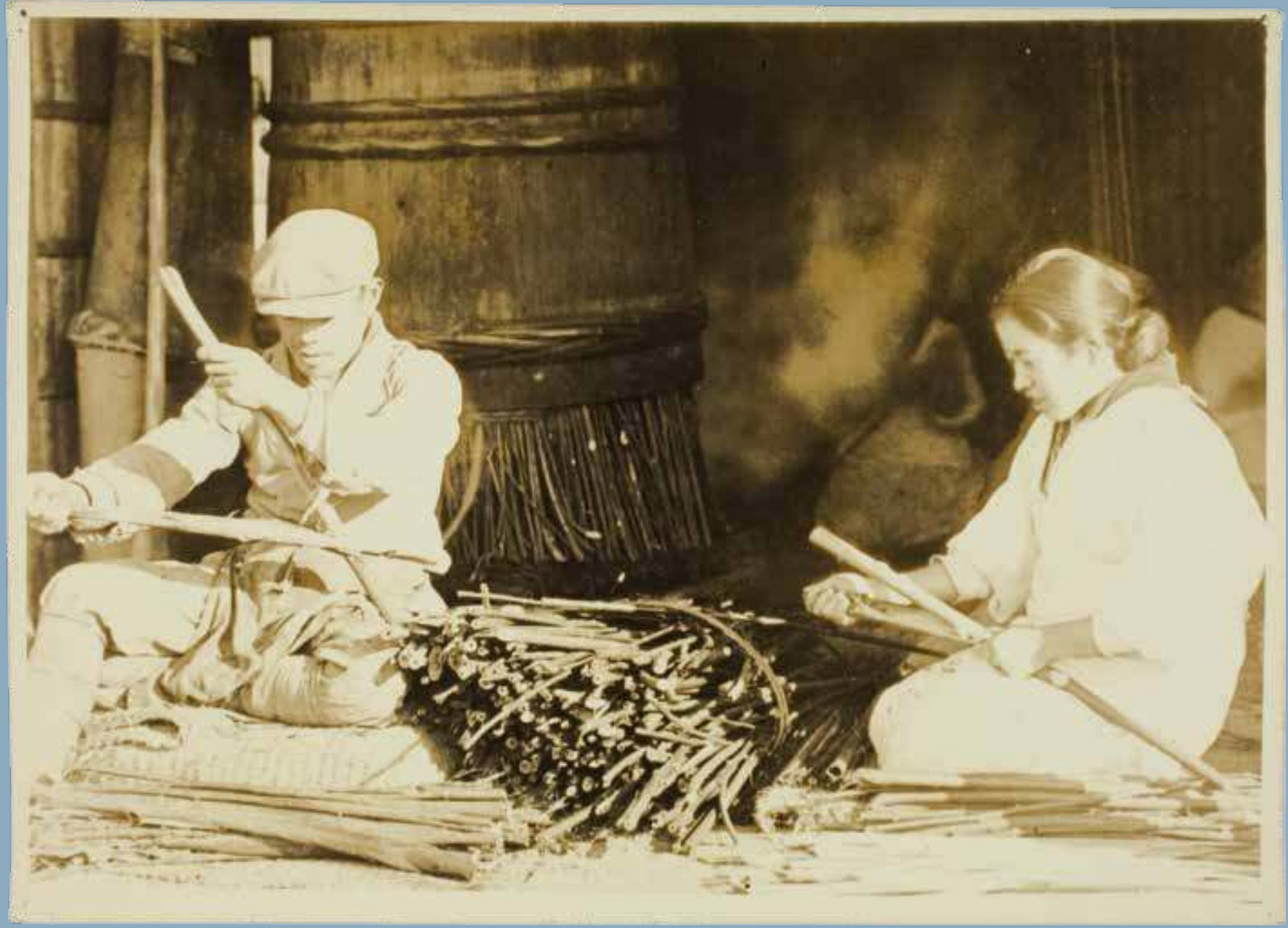




\section{Voler le feu du savoir pour l'éclairage commun}

Certaines cultures ont nommé ce qui se joue d'ineffable entre l'apprentissage et les apprenants, les techniques et le geste, le savoir et le faire. Là où, en français, nous devons réunir deux mots, savoir-faire, autrement dit réunifier sans cesse la théorie et la pratique, la langue japonaise possède le waza. Tout comme le «savoir-faire »-qui apparaît dans la première édition du dictionnaire de l'Académie française en 1694-, le «waza» est un terme ancien et en même temps contemporain, d'usage courant. Il est lui aussi général, du jardinage à la poterie... mais semble contenir une autre dimension quant à la délectation esthétique de faire et de voir faire, et une charge singulière quant aux modalités de transmission des habiletés matérielles.

Dans le vaste registre symbolique qu'évoque le mot waza, il en est une en particulier qui nous intéresse: l'expression idiomatique japonaise gijutsu wo nusumu (技術を盗む) signifie littéralement «voler les techniques». L'idée est celle d'une amélioration de ses propres savoir-faire et le gi de gijutsu est une lecture alternative de l'idéogramme waza lui-même (技).

«Voler les techniques» fait référence à une méthode d'apprentissage traditionnellement reconnue dans les métiers manuels japonais qui consiste pour l'apprenant à s'approprier le savoir du maître dans son dos, ce dernier n'offrant comme modèle d'apprentissage que la copie aveugle des gestes durant la journée. Les explications verbalisées sont rares et les secrets de l'enseignant jalousement gardés.

Pour l'étudiant, il ne reste donc qu'une solution: «voler » le savoir du professeur. L'expression évoque des récits d'apprentis rentrant la nuit, bougie à la main, dans l'atelier pour acquérir, par une analyse autonome, les secrets pratiques qui ne lui sont pas ouvertement communiqués pendant les années de sa formation. Cette méthode de (non-)enseignement crée une forte connivence entre les étudiants et explique les traditions techniques, c'est-à-dire les écoles, qui sont importantes dans la transmission du savoir manuel au Japon. 
Deux femmes battant la pulpe du kôzo (mûrier à papier, Broussonetia papyrifera) après cuisson pour en assouplir la fibre

Or, il est frappant de relever combien André Leroi-Gourhan s'est lui-même approprié au Japon de nombreuses méthodes qu'il n'a pourtant jamais verbalisées, malgré leur influence dans ses travaux ultérieurs. Réalise-t-on, aujourd'hui, à quel point celles-ci ont permis, en France, le développement de la technologie culturelle? Rappelons quelques faits. Si Leroi-Gourhan est devenu l'un des archéologues les plus éminents du xxe siècle, il n’a cependant jamais été formé à la discipline et ses premières fouilles professionnelles ne datent que de 1946, à l'âge de trente-cinq ans. Son initiation au travail archéologique de terrain est en réalité directement tributaire de son association fortuite à l'archéologue japonais Yawata Ichirô en 1937 (Soulier 2018: 54-55). Nous pourrions également mentionner que les études qu'il a menées tout au long de sa vie sur la technologie et la typologie des outils quotidiens ont été fortement influencées par sa rencontre avec de nombreux membres de l'Attic Museum de Shibusawa Keizô. Ce centre de recherche, noyau « d'objectologues » de tout poil, amateurs ou professionnels de l'anthropologie de la culture matérielle, donnera naissance quelques années plus tard à la bouillonnante Société japonaise d'ethnologie. Enfin, il faut souligner que certains concepts intéressants que l'on retrouve dans l'œuvre de Leroi-Gourhan sont une traduction à peine voilée d'idées japonaises. Citons la notion d'esthétique fonctionnelle qui donne son titre à un chapitre entier du second volume de Le Geste et la Parole (Leroi-Gourhan, 1964, chapitre 12). Leroi-Gourhan était proche des potiers Hamada Shôji et Kawai Kanjirô, membres fondateurs du Mouvement des arts populaires du Japon. L'esthétique fonctionnelle, théorisée à l'extrême par Yanagi Sôetsu (Marquet 2009: 18), figure de proue du Mouvement, était au cour de leur démarche artistique quand Leroi-Gourhan fit leur connaissance selon les principes vertueux du yô no bi (用の美), littéralement «la beauté de la fonction».

France et Japon possèdent donc

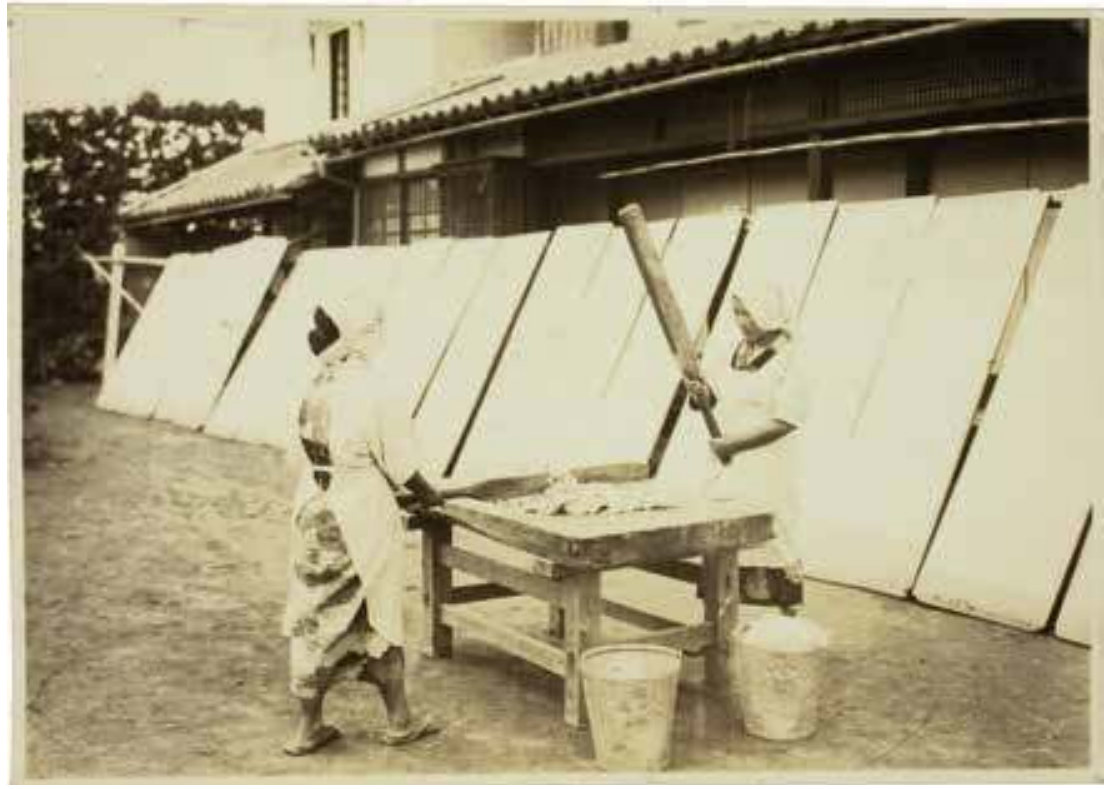
des liens insoupçonnés en matière de waza, et les filiations théoriques de leurs sciences de l'Homme ne sont certainement pas aussi éloignées que les distances géographiques le laissent penser.

Le présent numéro de Techniques ECulture en témoigne à sa façon en constituant le prolongement naturel de ces transferts de savoirs, mais cette fois en plein jour et de façon immédiatement croisée, à l'initiative de Frédéric Joulian.

Quand celui-ci, encore étudiant, découvre la revue de primatologie japonaise Primates au Muséum national d'histoire 
naturelle, il ne se doute pas qu'en 1988, menant un terrain d'éthologie en Côte d'Ivoire, il rencontrait ses alter ego japonais, juste de l'autre côté de la frontière, en Guinée. À partir de 2009, après avoir invité le chercheur Gen Yamakoshi à l'École des hautes études en sciences sociales, Frédéric Joulian multiplie les séjours d'enseignement sur l'évolution humaine aux universités de Kyoto et de Kobe notamment. Ces séjours l'amènent à rencontrer les chercheurs de l'Institut de recherche pour l'humanité et la nature, où il présente en 2017 Réparer le monde (nº5-66), avec Yann Philippe Tastevin et Yoann Moreau, également auteur dans le présent numéro. Enfin, sa rencontre avec le malien Oussouby Sacko, technologue et architecte, désormais président de l'université de Kyoto Seika, qui donne la postface à cet ouvrage, débouche en 2019 sur l'aventure du washi, une enquête multidisciplinaire et en manga sur la fabrication de ce papier traditionnel.

Pendant toutes ces années, le waza n'est jamais loin. Il s'approche à pas discret, collectivement, une première fois avec l'ouvrage Dire le savoir-faire (D'Onofrio \& Joulian 2006, Cobbi 2006), puis dans Geste et Matière (n57) (Joulian 2011).

C'est dans ce parcours de plus de trente ans, depuis les questions que pose l'apprentissage naturel ou culturel, à l'artisanat du papier au Japon - dont André Leroi-Gourhan, là encore de façon presque totalement méconnue ${ }^{1}$, a photographié des ateliers - que se trouve la «fabrique » au fond très wazéenne de ce numéro.

\section{Notes}

1. La rédaction remercie Nathan Schlanger d'avoir signalé ce fonds.

\section{Iconographie}

Image d'ouverture. Couple écorçant les branches de kôzo (mûrier à papier, Broussonetia papyrifera) après étuvage de celles-ci. Photographe anonyme, mission A. Leroi-Gourhan au Japon 1937-1939, 10,6 x 14,7 cm, tirage sur papier baryté, PP0210220 @ Musée du quai BranlyJacques Chirac.

\section{Références}

Cobbi, J. 2006 «"Le pays de la main". Waza ou le savoirfaire au Japon » in S. D'Onofrio \& F. Joulian dir. Dire le savoir-faire. Gestes, techniques et objets. Paris: L'Herne: 111-120 (Cahiers d'anthropologie sociale 1).

Joulian, F. dir. 2011 Geste et Matière. André Leroi-Gourhan, découvertes japonaises. Techniques\& Culture 57.

Leroi-Gourhan, A. 1964 Le Geste et la Parole, II La mémoire et les rythmes. Paris: Albin Michel.

\section{Pour citer l'article}

1. Photographe anonyme, mission A. Leroi-Gourhan au Japon 1937-1939, 10,6 x 14,7 cm, tirage sur papier baryté, PP0210225 @ Musée du quai Branly-Jacques Chirac.

Marquet, C. 2009 «Yanagi Sôetsu et l'invention des "arts populaires": remise en perspective» in C. Marquet \& J.-M. Butel dir. L'invention des «arts populaires», Yanagi Sôetsu et le Mingei. Paris: Publications Langues O': 18.

Soulier, Ph. 2018 André Leroi-Gourhan [1911-1986] Une vie. Paris: CNRS Éditions: 54-55.

D’Onofrio, S. \& F. Joulian dir. 2006 «Dire le savoir-faire. Gestes, techniques et objets», Cahiers d'anthropologie sociale 1. Paris: L'Herne.

Bartholeyns, G., Kunik, D. \& A. Vallard 2021 «Voler le feu du savoir pour l'éclairage commun», TechniquesE Culture 76 «Waza: l'art ineffable de l'apprentissage», p. 6-9. 